\title{
Prevention of Overweight and Hypertension through Cardiorespiratory Fitness and Extracurricular Sport Participation among South African Schoolchildren
}

\author{
Siphesihle Nqweniso ${ }^{1, *(\mathbb{D}}$, Cheryl Walter ${ }^{1}$, Rosa du Randt ${ }^{1}{ }^{\circledR}$, Ann Aerts ${ }^{2}$, Larissa Adams ${ }^{1}$, \\ Jan Degen ${ }^{3}$, Stefanie Gall ${ }^{3}$, Zaahira Gani ${ }^{4}$, Nandi Joubert ${ }^{5,6}$, Ivan Müller ${ }^{3}{ }^{1}$, Danielle Smith ${ }^{1}$, \\ Harald Seelig ${ }^{3}$, Peter Steinmann ${ }^{5,6} \mathbb{D}^{\text {, }}$, Nicole Probst-Hensch ${ }^{5,6}$, Jürg Utzinger ${ }^{5,6}$, Uwe Pühse ${ }^{3}$ (i) \\ and Markus Gerber ${ }^{3}$ (1) \\ 1 Department of Human Movement Science, Nelson Mandela University, Port Elizabeth 6001, South Africa; \\ cheryl.walter@mandela.ac.za (C.W.); rosa.durandt@mandela.ac.za (R.d.R.); \\ larissa.adams@mandela.ac.za (L.A.); danielle.smith@mandela.ac.za (D.S.) \\ 2 Novartis Foundation, 4056 Basel, Switzerland; ann.aerts@novartis.com \\ 3 Department of Sport, Exercise and Health, University of Basel, 4052 Basel, Switzerland; \\ jan.degen@unibas.ch (J.D.); stefanie.gall@unibas.ch (S.G.); ivan.mueller@unibas.ch (I.M.); \\ harald.seelig@unibas.ch (H.S.); uwe.puehse@unibas.ch (U.P.); markus.gerber@unibas.ch (M.G.) \\ 4 Novartis, 4056 Basel, Switzerland; zaahira.gani@novartis.com \\ 5 Swiss Tropical and Public Health Institute, 4051 Basel, Switzerland; nandi.joubert@unibas.ch (N.J.); \\ peter.steinmann@swisstph.ch (P.S.); nicole.probst@swisstph.ch (N.P.-H.); juerg.utzinger@unibas.ch (J.U.) \\ 6 University of Basel, 4001 Basel, Switzerland \\ * Correspondence: fnqweniso@mandela.ac.za; Tel.: +27-41-504-4352
}

Received: 14 July 2020; Accepted: 11 August 2020; Published: 14 August 2020

\begin{abstract}
Hypertension and overweight are growing public health concerns in school-aged children. We examined whether cardiorespiratory fitness and sport participation contribute to the prevention of hypertension and overweight. We conducted a cluster-randomized controlled trial with 853 children aged 8-13 years in eight primary schools in Port Elizabeth, South Africa. Cardiorespiratory fitness, sport participation, body mass index, and blood pressure were assessed at baseline and after a physical activity intervention, which took place at two time-points (July-September 2015 and February-April 2016) for 10 weeks each. Mixed logistic regressions were employed to analyze the data. At baseline, $18.8 \%$ of the children were classified as overweight/obese and $13.5 \%$ as hypertensive. High cardiorespiratory fitness and high sport participation were negatively associated with overweight/obesity, while high sport participation was associated with lower risk for hypertension. Longitudinally, normal weight children who initially had higher cardiorespiratory fitness showed less decrease in this variable, while those who participated in the physical activity intervention were less likely to become overweight/obese. High cardiorespiratory fitness and sport participation are linked with children's weight status. Children who are fit and participate regularly in sport outside school hours are less likely to be hypertensive. Our findings highlight the importance of regular extracurricular physical activity and maintaining cardiorespiratory fitness levels.
\end{abstract}

Keywords: cardiorespiratory fitness; hypertension; obesity; overweight; physical activity; schoolchildren; sport participation; South Africa

\section{Introduction}

Globally, hypertension and obesity are common health problems and have become major public health concerns, increasingly so in school-aged children and adolescents [1,2]. In South Africa, 
for example, the prevalence of childhood overweight and obesity has increased over the previous decade from $1.1 \%$ to $9.5 \%$ in boys and from $1.4 \%$ to $16.5 \%$ in girls. These increases are likely to translate into a higher prevalence of hypertension in children and adolescents [3]. Several studies have documented a high prevalence of hypertension in Black South African children ranging from $1 \%$ to $25.9 \%$ [4-6]. This is a concern because evidence from a longitudinal cohort-the Young Finns study-reported that blood pressure (BP) tracks from childhood to adulthood [7]. Indeed, a South African study reported a high prevalence of high BP, which tracks from early childhood into late adolescence, with overall tracking coefficients ranging from 0.20 to 0.57 for systolic $\mathrm{BP}$ and from 0.17 to 0.51 for diastolic BP in boys and girls [8].

Although hypertension is defined differently in children than in adults, a study found that $3 \%$ to $4 \%$ of all obese children, and approximately $30 \%$ of the obese adolescents have high BP associated with obesity [2]. In this regard, Muntner et al. [9] found that systolic and diastolic BP of children were, respectively, $1.4 \mathrm{mmHg}$ and $3.3 \mathrm{mmHg}$ higher in the period 1999-2000 than in the period 1988-1994 and attributed this increase to the higher prevalence of overweight children. With the rising prevalence of obesity and high BP and the established association between obesity and high BP in school-aged children and adolescents, it has been recommended that interventions, including physical activity (PA), should start early on in life $[5,10]$.

The trend for rising obesity and elevated BP, which starts during childhood and tracks into adulthood $[7,8,11]$, coupled with the established associations between obesity, hypertension, and diabetes in adults, means that obese children are at particularly high risk of becoming diabetic and hypertensive as they grow older [12]. Hence, lifestyle changes aimed at weight control and sufficient PA are recommended for children [2]. Research with overweight and obese children has demonstrated that lifestyle interventions incorporating a dietary component along with exercise or behavioral therapy can lead to improvements in both weight and cardiometabolic risk factors, which includes high BP [13]. Overall PA through play, active transport, leisure time activity, exercise, and sport participation have been shown to have beneficial effects on children's metabolic risk profile, including BP $[10,14]$. The Health Survey for England study found that PA and cardiorespiratory fitness were associated with cardiometabolic risk factors in adults, with PA especially associated with body mass index (BMI) and cardiorespiratory fitness associated with both BMI and systolic BP [15]. Similar observations were made in a longitudinal study in children, where higher cardiorespiratory fitness levels were associated with lower systolic BP [16]. Furthermore, studies reported that maintaining an adequate level of cardiorespiratory fitness has the potential to delay the development of hypertension in adulthood $[16,17]$.

The purpose of this study was four-fold. First, to estimate the prevalence of hypertension and overweight/obesity in South African children attending primary schools in disadvantaged areas. Second, to examine whether and to what extent cardiorespiratory fitness and extracurricular sport participation contribute to the distinction of children who are (i) overweight versus normal weight and (ii) hypertensive versus non-hypertensive. Third, to determine whether baseline levels and changes in cardiorespiratory fitness and sport participation are related to overweight development among children who were initially classified as normal weight. Fourth, to assess whether baseline levels and changes in cardiorespiratory fitness and sport participation are related to hypertension rates among children who were initially classified as non-hypertensive.

\section{Materials and Methods}

The data reported in this paper stem from a cluster-randomized controlled trial, the "Disease Activity and Schoolchildren's Health" (DASH) study [18]. The main purpose of the DASH study was to examine the efficacy of a school-based health promotion program on children's health and development. The program was conducted twice, first between July and September 2015 and then between February and April 2016, each period lasting for 10 weeks and included PA, health education, deworming, 
and nutritional supplementation. Data assessments took place at two time-points, at baseline (February 2015), and post-intervention (May 2016).

Approval of the study was obtained from the responsible ethical committees in South Africa (the Nelson Mandela University; reference no. H14-HEA-HMS-002) and Switzerland (Ethics Committee Northwest and Central Switzerland; reference no. 2014-179), and the Eastern Cape Departments of Education and Health. The study is registered at ISRCTN registry under controlled-trials.com (identifier: ISRCTN68411960). Detailed written and oral information was provided to parents and legal guardians of participating children, explaining the purpose, procedures, potential risks, and benefits of the study. Subsequently, parents and legal guardians were invited to provide written informed consent before data assessment commenced. Children provided oral assent.

\subsection{Participants and Procedures}

Children were recruited from grade 4 classes in eight quintile 3 schools. All schools were located in the Port Elizabeth area, in the Eastern Cape Province of South Africa. Quintile 3 schools are considered as "disadvantaged" schools and have generally poor ratings with reference to national poverty tables, income levels, dependency ratios, and literacy rates in a specific area. School-selection procedures have been described in more detail in the study protocol [18]. Children were included in our study if they were willing to participate, had written informed consent of a parent/guardian, did not simultaneously participate in other clinical trials during the study period, and did not suffer from medical conditions that might prevent participation in the study, as determined by qualified clinical personnel.

At baseline, all children ( $n=1009,508$ boys, 501 girls) were between 8 and 13 years old. At baseline, 853 children ( 435 boys, 418 girls) had complete data with regard to cardiorespiratory fitness, sport participation, and weight status, whereas 842 children ( 433 boys, 409 girls) had complete data with regard to cardiorespiratory fitness, sport participation, and BP. For the prospective analyses, 96 children ( 49 boys, 47 girls) were excluded, as they were lost to follow-up because they left school, were unavailable at the post-intervention data assessment, or did not have valid post-intervention BMI data. For the same reason, 160 children (91 boys, 69 girls) were excluded because they left school, were unavailable at the post-intervention data assessment, or did not have valid post-intervention BP data. Thus, the longitudinal sample comprised of 757 children (386 boys, 371 girls, $M=9.5 \pm 0.9$ years at baseline) for BMI, and 682 (342 boys, 340 girls, $M=9.5 \pm 0.9$ years at baseline) for BP.

Univariate analyses of variance (ANOVAs) and $\chi^{2}$ tests showed that children included versus children excluded in the longitudinal data analyses did not significantly differ with regard to any of the predictor variables (cardiorespiratory fitness, sport participation, intervention condition: PA versus no PA intervention), the outcome variables (BMI, systolic and diastolic BP), or the covariates (sex, socioeconomic status, and ethnicity). The only two significant group differences were found between children for age and class-in-school; excluded children were approximately 2 months older, and were overrepresented in some classes compared to others $(p<0.05)$.

\subsection{Measures}

The same measures were assessed at baseline and after completion of the intervention. The data assessment was carried out class-wise during official school hours by trained researchers.

\subsection{Assessment of Children's Weight Status}

Children's weight status was assessed via the BMI, based on their height and weight. To measure body weight, we used an electronic platform scale (Micro T7E, Optima Electronics; George, South Africa), with measurements to the nearest of $0.1 \mathrm{~kg}$. To assess body height, a Seca Stadiometer (Surgical SA; Johannesburg, South Africa) was employed with height measured to the nearest $0.1 \mathrm{~cm}$. We used the following formula to calculate BMI: weight (in $\mathrm{kg}$ )/ $/ \mathrm{height}^{2}$ (in m). Additionally, we calculated BMI-for-age scores, stratified by sex, using the growth reference of the World Health Organization (WHO) [19]. Children were classified as overweight if they had a BMI-for-age $>+1$ standard deviation 
(SD) above the WHO growth reference median. Children were considered obese if their BMI-for-age was $>+2 \mathrm{SD}$ above the WHO growth reference.

\subsection{Assessment of $B P$}

To assess BP, we used a validated oscillometric digital BP monitor (Omron ${ }^{\circledR}$ M6 AC; Hoofddorp, The Netherlands). The measurement was performed in a sitting position after the child had been seated for approximately $5 \mathrm{~min}$. The bottom of the cuff was placed about $4 \mathrm{~cm}$ above the elbow of the left arm with the palm facing upwards. We ensured that the cuff-size $(17-22 \mathrm{~cm})$ was appropriate for children's range of arm-circumferences (Omron ${ }^{\circledR}$ CS2 Small cuff; Hoofddorp, The Netherlands). For normal and hypertensive BP, reference values exist for children living in Europe [20] and the United States of America [21]. By contrast, no such values exist for African children [22]. Accordingly, we used reference tables from a nationally representative sample of 12,199 non-overweight German children (aged 3-17 years), in which standardized BP assessments were applied with a comparable automated oscillometric device [20]. Based on percentiles taking into account children's age, sex, and height, children were considered normotensive if they were below the 90th percentile, prehypertensive if they were between the 90th and 94th percentile, and hypertensive from the 95th percentile. In the standardization study with German children, BP readings were taken twice, with the first reading generally resulting in higher values $(1.5-1.9 \mathrm{mmHg}$ and $1.8-2.2 \mathrm{mmHg}$ for systolic and diastolic BP, respectively) than the second one [20]. To avoid an overestimation of hypertension in our sample and, based on the fact that we could only measure once, we corrected the systolic and diastolic BP scores by subtracting the difference identified in the standardization study between the first and the second reading from the mean of our two readings (taking into account children's age and sex).

For the purpose of the present analyses, children were considered hypertensive if they were classified as hypertensive with reference to both systolic and diastolic BP, whereas they were considered non-hypertensive when they were (i) normotensive or prehypertensive with regard to both systolic and diastolic blood pressure or (ii) if they were classified as hypertensive only with reference to either systolic or diastolic BP.

\subsection{Assessment of Cardiorespiratory Fitness}

Children's cardiorespiratory fitness was assessed with the $20 \mathrm{~m}$ shuttle run test, based on a standardized test protocol [23]. The speed (determined by a sound signal) steadily increased by $0.5 \mathrm{~km} / \mathrm{h}$ during the test. Children had to stop running when they were no longer able to follow the speed of the sound signal. Based on the number of fully completed $20 \mathrm{~m}$ laps, we estimated children's maximum oxygen uptake $\left(\mathrm{VO}_{2} \mathrm{max}\right)$, using a standard protocol [24]. The reliability and validity of the $20 \mathrm{~m}$ shuttle run test has been established in previous research $[25,26]$.

\subsection{Assessment of Exercise and Sport Participation}

To assess extracurricular sport participation, we invited children to answer a single question taken from the Health-Behaviour of School-Aged Children (HBSC) survey [27]: "Outside of school hours, how often do you usually practice sports during your free time?" Answering options ranged from 0 to 7 days. Previous studies showed that this question has acceptable validation when compared to PA levels assessed by accelerometers [28,29].

\subsection{Assessment of Covariates}

Age, sex, and socioeconomic status (SES) were assessed via children's self-reports. SES was assessed with a nine-item self-report questionnaire about housing characteristics, ownership of durable assets (e.g., washing machine), and household-level living standards. Scores of the SES index range from 1 to 9 , with higher scores being indicative of higher family SES. 


\subsection{Statistical Analyses}

Means $(M)$, standard deviations $(S D)$, minimum, maximum, skewness, and kurtosis are reported for all study variables. Prevalence rates are reported as frequencies $(n)$ and percentages (\%). To assess whether hypertension is associated with children's age, sex, and SES, we performed a series of $\chi^{2}$ tests and analyses of variance (ANOVAs). To examine cross-sectionally whether children classified as hypertensive differ from their non-hypertensive peers with regard to their cardiorespiratory fitness and their sport behavior, we carried out mixed logistic regression analyses (before and after controlling for potential confounders). Class membership was considered as a random intercept to take into account the nested nature of the data (students recruited from different classes attending different schools). The same statistical procedures were used to test differences between overweight and non-overweight children. To examine whether and to what extent cardiorespiratory fitness and sport contribute to the prevention of overweight and hypertension, only children were included in the analyses who were initially classified as non-overweight or normotensive. We then performed separate mixed logistic regression analyses to examine whether baseline levels and changes in cardiorespiratory fitness and sport participation predicted overweight and hypertension at post-intervention.

Class membership was used as a random intercept in all analyses, and separate analyses were carried out before and after, taking into account intervention conditions (PA intervention versus no PA intervention) and potential confounders. All statistical analyses were carried out with SPSS version 26 for Mac (IBM Corporation; Armonk, United States of America). The level of statistical significance was set at $p<0.05$ across all analyses.

\section{Results}

\subsection{Descriptive Statistics}

Descriptive statistics are presented in Table 1. At baseline, 38 children (4.5\%) were classified as underweight and 655 children (77\%) were classified as normal weight, whereas 160 children $(18.8 \%)$ were classified as overweight or obese. Furthermore, with regard to systolic BP, 586 (70\%) of the children were classified as normotensive, $57(7 \%)$ as prehypertensive, and $199(23 \%)$ as hypertensive. With regard to diastolic BP, 578 children (69\%) were classified as normotensive, $63(7 \%)$ as prehypertensive, and 201 $(24 \%)$ as hypertensive. At baseline, a total of 114 children (13.5\%) were classified as hypertensive with reference to both systolic and diastolic BP. At baseline, 101 children (11.8\%) reported that they did not engage in extracurricular exercise/sport activities, whereas 134 children were active once per week $(15.7 \%), 383$ children ( $35.8 \%$ ) were active on $2-4$ days per week, and 313 children (36.7\%) were active on 5-7 days per week.

Table A1 (Appendix A) summarizes changes with regard to BMI and BP classifications from follow-up. Based on the BMI and combined BP index, the classifications were relatively stable, whereas a stronger fluctuation (in both directions) was found for the specific classifications based on children's systolic and diastolic BP.

Based on BMI categories (underweight, normal weight vs. overweight), univariate ANOVAs yielded a significant main effect for cardiorespiratory fitness, $F(2850)=26.4, p<0.001, \eta^{2}=0.059$, and extra-curricular exercise/sport activity, $F(2850)=9.2, p<0.001, \eta^{2}=0.021$. However, Bonferroni post-hoc tests revealed that underweight and normal weight children did not differ from each other with regard to cardiorespiratory fitness, $p=1.00$ (underweight: $M=49.1, S D=4.0$; normal weight: $M=49.7, S D=4.3$ ) and extra-curricular exercise/sport activity, $p=0.81$ (underweight: $M=4.1, S D=2.6$; normal weight: $M=3.7, S D=2.5$ ), whereas underweight and normal weight children statistically significantly $(p<0.01)$ differed from overweight peers in both variables (cardiorespiratory fitness: $M=47.0, S D=3.8$; extra-curricular exercise/sport participation: $M=2.8, S D=2.3$ ). We therefore decided to combine underweight and normal weight children in the same category of "non-overweight" children for all subsequent analyses. 
In the sample of non-overweight children included in the prospective analyses to predict the development of overweight/obesity across time $(n=611)$, repeated measures analyses of variance (rANOVAs) with a within-subject factor time (baseline vs. post-intervention) revealed that cardiorespiratory fitness decreased from baseline $(M=49.7, S D=4.2)$ to post-intervention $(M=47.6, \mathrm{SD}=4.6), F(1610)=150.9, p<0.001, \eta^{2}=0.198$. A decrease was also found for sport participation (baseline: $M=3.7, S D=2.5$; post-intervention: $M=3.0, S D=2.0$ ), $F(1610)=26.7, p<0.001$, $\eta^{2}=0.042$.

Similarly, in the sample of non-hypertensive children used for the prospective analyses to predict the development of hypertension $(n=583)$, we observed a significant decrease in cardiorespiratory fitness from baseline $(M=49.3, S D=4.2)$ to post-intervention $(M=46.9, \mathrm{SD}=4.6), F(1582)=213.8$, $p<0.001, \eta^{2}=0.274$. A decrease was also found for sport participation (baseline: $M=3.7, S D=2.5$; post-intervention: $M=3.0, S D=2.0), F(1582)=25.6, p<0.001, \eta^{2}=0.042$.

Table 1. Baseline descriptive statistics of all study variables, for the total sample $(N=853)$.

\begin{tabular}{|c|c|c|c|c|c|c|}
\hline $\begin{array}{l}\text { Social and Demographic } \\
\text { Background }\end{array}$ & $M$ & $S D$ & Min & $\operatorname{Max}$ & Skewness & Kurtosis \\
\hline Age (years) & 9.5 & 1.0 & 8 & 13 & 0.9 & 1.6 \\
\hline \multirow[t]{2}{*}{ Socioeconomic background (0-9) } & 7.5 & 2.1 & 0 & 9 & -1.5 & 1.3 \\
\hline & $N$ & $\%$ & & & & \\
\hline \multicolumn{7}{|l|}{ Gender } \\
\hline Girls & 413 & 49.8 & & & & \\
\hline Boys & 416 & 50.2 & & & & \\
\hline \multicolumn{7}{|l|}{ Ethnicity } \\
\hline Black African & 509 & 61.8 & & & & \\
\hline Colored & 315 & 38.2 & & & & \\
\hline Exercise, sport and fitness & $M$ & $S D$ & Min & Max & Skewness & Kurtosis \\
\hline \multirow{2}{*}{$\begin{array}{l}\text { Exercise and sport participation } \\
\text { Cardiorespiratory fitness } \\
\left(\mathrm{VO}_{2} \mathrm{max}\right)\end{array}$} & 3.5 & 2.5 & 0 & 7 & 0.2 & -1.3 \\
\hline & 49.1 & 4.3 & 32.2 & 61.9 & 0.3 & 0.1 \\
\hline Body mass & $M$ & $S D$ & Min & Max & Skewness & Kurtosis \\
\hline Height (cm) & 133.2 & 7.1 & 109.2 & 165.3 & 0.3 & 0.4 \\
\hline Weight (kg) & 30.4 & 7.4 & 15.8 & 87.4 & 2.0 & 7.7 \\
\hline Body mass index (BMI) $\left(\mathrm{kg} / \mathrm{m}^{2}\right)$ & 17.0 & 3.0 & 11.5 & 41.7 & 2.4 & 10.6 \\
\hline BMI-for-age (z-score) & 0.0 & 1.2 & -3.67 & 4.32 & 0.3 & 0.5 \\
\hline \multicolumn{7}{|l|}{ Blood pressure } \\
\hline Systolic blood pressure (mmHg) & 106.6 & 13.4 & 61 & 158 & 0.3 & 0.5 \\
\hline \multirow[t]{2}{*}{ Diastolic blood pressure (mmHg) } & 67.7 & 10.7 & 36 & 130 & 1.1 & 3.8 \\
\hline & $N$ & $\%$ & & & & \\
\hline \multicolumn{7}{|l|}{ BMI classification } \\
\hline Underweight & 38 & 4.5 & & & & \\
\hline Normal weight & 655 & 76.8 & & & & \\
\hline Overweight/obese & 160 & 18.8 & & & & \\
\hline \multicolumn{7}{|l|}{ Hypertension classification } \\
\hline Normotensive & 728 & 86.5 & & & & \\
\hline Hypertensive & 114 & 13.5 & & & & \\
\hline
\end{tabular}

\subsection{BMI Classification and Sociodemographic Background}

At baseline, girls were more likely to be classified as overweight/obese than boys ( $24 \%$ vs. $15 \%$ ), $\chi^{2}(1853)=8.5, p<0.01, \varphi=0.099$. Non-overweight children were significantly younger than their overweight peers, $F(1851)=22.4, p<0.001, \eta^{2}=0.026(M=9.6, S D=1.0$ vs. $M=9.2, S D=0.8$ 
years), whereas overweight children reported a higher SES compared to non-overweight children, $F(1851)=14.4, p<0.001, \eta^{2}=0.017(M=8.0, S D=1.8$ vs. $M=7.4, S D=2.1)$.

\subsection{Hypertension Classification and Sociodemographic Background}

Based on the combined BP index, at baseline, boys and girls were similarly represented in the group classified as normotensive (boys: $52 \%$, girls: $48 \%$ ) and hypertensive (boys: $48 \%$, girls: $52 \%$ ), $\chi^{2}(1842)=0.5, p=\mathrm{ns}, \varphi=0.025$. Also, no significant differences were found between normotensive and hypertensive children with regard to their age, $F(1840)=2.8, p=\mathrm{ns}, \eta^{2}=0.003$ (normotensive: $M=$ 9.5, $S D=1.0$, hypertensive: $M=9.4, S D=0.9$ ), and $\operatorname{SES}, F(1840)=1.7, p=\mathrm{ns}, \eta^{2}=0.002$ (normotensive: $M=7.5, S D=2.1$, hypertensive: $M=7.2, S D=2.3$ ).

\subsection{Cross-Sectional Associations between Cardiorespiratory Fitness and Sport Participation}

As shown in Table A2 (Appendix B), after controlling for the nested nature of the data, children with high cardiorespiratory fitness levels and with higher sport participation were less likely to be classified as overweight/obese. The relationship persisted after controlling for social and demographic background. Table A2 (Appendix B) further reveals that children who report higher sport participation were also less likely to be classified as hypertensive. No such association was found for cardiorespiratory fitness. The association for sport participation persisted after controlling for potential confounders.

\subsection{Prospective Associations between Cardiorespiratory Fitness and Sport Participation}

Table A3 (Appendix C) shows that, after taking into account the clustered nature of the data, among initially normotensive children, those who had higher cardiorespiratory fitness levels and/or who had a less pronounced decrease in cardiorespiratory fitness from baseline to post-intervention were less likely to become overweight/obese until follow-up. Contrary to the cross-sectional analyses, no significant association was identified for sport participation in the prospective analyses. The association with baseline levels and changes in cardiorespiratory fitness remained significant after accounting for socio-demographic background, and intervention condition. Interestingly, however, normal weight children who took part in the PA intervention were also less likely to become overweight/obese compared to peers assigned to the control group without PA intervention.

By contrast, no significant prospective associations were found with hypertension status as dependent variable. In other words, none of the considered predictors was able to explain why initially normotensive children became hypertensive at post-intervention.

\section{Discussion}

The key findings of the present study were that, at baseline, $18.8 \%$ of 853 children were classified as overweight or obese. A total of $13.5 \%$ of 842 children were classified as hypertensive for both systolic and diastolic BP. Girls were more likely to be classified as overweight/obese as compared to boys $(24 \%$ vs. $15 \%)$. Cross-sectionally, high cardiorespiratory fitness and high sport participation were negatively associated with BMI, while high sport participation was associated with low levels of hypertension. In the longitudinal analyses, normal weight children who had higher cardiorespiratory fitness at baseline or whose cardiorespiratory fitness decreased less from baseline to post-intervention were less likely to become overweight/obese at follow-up. Moreover, normal weight children who participated in the PA intervention component also were less likely to become overweight/obese until post-intervention.

Taken together, the current study pursued four specific objectives, which are offered for discussion. The first objective was to deepen our understanding of the prevalence of overweight/obesity and hypertension in South African children attending primary schools in disadvantaged areas. Our results regarding overweight in the group of 8 to 13 year-old children indicates a prevalence of $18.8 \%$ for overweight/obesity, which is higher than what has been reported in previous South African studies $(3-13 \%)[5,6,14]$. Our findings corroborate those of other studies indicating that girls are more likely 
to be classified as overweight/obese compared to boys [4,5]. Factors proposed to play a role in this gender difference include possible differences in the energy needs between boys and girls, in the timing of sexual maturation [30], in the levels of PA, and in behavioral or cultural phenomena [31]. We reported a prevalence of $23 \%(n=199)$ and $24 \%(n=201)$ for systolic and diastolic BP, respectively. With reference to both systolic and diastolic BP, we found a prevalence of $13.5 \%$, which is slightly higher than the $5.8 \%$ and $11.4 \%$ (boys and girls) indicated in a study conducted by Monyeki, Kemper and Makgae [4] more than 10 years ago in the Limpopo province of South Africa in children aged 6-13 years. Research has shown that, over the past few decades, the prevalence of hypertension has increased along with increasing childhood overweight and obesity [9]. The prevalence of hypertension in children and adolescents reported in other studies varied from $4 \%$ to as high as $25 \%$ in children aged 5-18 years $[5,8,14]$. Findings from other studies in sub-Saharan African countries reported a lower prevalence of hypertension; $10 \%$ in Congo-Brazzaville and 5\% in Nigeria [32,33]. Similarly, the prevalence of overweight in the study in Nigeria (5.7\%) and Congo-Brazzaville (7.8\%) is lower than the one reported in our study $[32,33]$. These findings can be attributed to the nutritional transition taking place in South Africa that has seen a shift from undernutrition to overnutrition due to a more westernized diet [34]. According to Steyn et al., other sub-Saharan African countries are also going through this nutrition transition, but are still at an early stage [35].

The second objective of our study was to examine whether and to what extent cardiorespiratory fitness and extracurricular sport participation contribute to the distinction of children who are (i) overweight versus normal weight, and (ii) hypertensive versus non-hypertensive. Our results showed that children who report higher sport participation were less likely to be classified as hypertensive. The authors of the European Youth Heart study observed that total PA was significantly and independently correlated with BP [10]. Another study revealed that adolescents who reported higher cardiorespiratory fitness at baseline had lower systolic BP after a two-year follow-up compared with their peers with lower cardiorespiratory fitness [16]. In the current study, no such correlation was found between cardiorespiratory fitness and BP; however, children with high cardiorespiratory fitness and sport participation were less likely to be overweight/obese. Similar results were reported with cardiorespiratory fitness to be significantly and negatively correlated with BMI, waist circumference, and percentage body fat $[10,14]$. Having adequate cardiorespiratory fitness and PA levels may have the potential to extend normal BP and reduce overweight over time, thus delaying the development of hypertension in adulthood. Therefore, increasing PA and decreasing the amount of time spent being sedentary have been established to have beneficial effects on cardiovascular and metabolic health in children $[10,16]$.

The third objective of our study was to establish whether baseline levels and changes in cardiorespiratory fitness and sport participation contribute to the prevention of overweight among children who were initially classified as normal weight. We found that normal weight children who had high baseline cardiorespiratory fitness and/or those who decreased less in cardiorespiratory fitness from baseline to post-intervention were less likely to become overweight/obese until follow-up. Our findings confirm results reported in previous studies that showed that children and adolescents with high cardiorespiratory fitness have a low risk of being overweight/obese $[6,10,14]$. This finding is important because adolescents that have low fitness levels have a six times higher risk of being classified as overweight/obese [14]. Additionally, it has been established that overweight/obese children have a five times higher risk of being hypertensive compared to those with normal weight status [36]. The association between high levels of overweight with low PA levels calls for urgent interventions that encourage an increase in overall PA and physical fitness in children, especially in light of the rising prevalence of overweight/obesity and hypertension reported in children and adolescents [3]. Our study also confirms that levels of cardiorespiratory fitness and extracurricular sport participation significantly decreased across the entire study period. Hence, interventions should be implemented as early as childhood because overweight and obesity are associated with significantly increased risk of later cardiometabolic morbidity (diabetes, hypertension, ischaemic heart disease, and stroke) 
in adult life [37]. Finally, our findings showed that, among normal weight children, participation in a school-based intervention program with a PA component reduced the likelihood that children became overweight/obese during the study period. This is in line with previous studies showing that school-based PA interventions can contribute to the prevention of overweight/obesity among school-aged children $[38,39]$. This is in line with the recommendation of WHO to target schools as a setting for the promotion of physically active lifestyles among children and adolescents [40].

Our fourth and final objective was to investigate whether baseline levels and changes in cardiorespiratory fitness and sport participation contribute to the prevention of hypertension among children who were initially classified as non-hypertensive. We identified no significant association between cardiorespiratory fitness and sport participation and the development of hypertension among non-hypertensive children. Other studies have reported opposing results in this regard. For example, a two-year longitudinal study reported that adolescents with high cardiorespiratory fitness at baseline presented lower systolic BP at follow-up than those with low cardiorespiratory fitness [16]. Other studies reported that total PA and its subcomponents (time spend sedentary, low PA, moderate PA, and vigorous PA) were significantly correlated with most metabolic risk factors, such as elevated BP [10]. Cardiorespiratory fitness was significantly and independently correlated with multiple individual risk factors and with clustered metabolic risk factors in the European youth heart study [10]. The association between cardiorespiratory fitness and clustered risk is mediated by adiposity, while the association between PA and risk factors is independent of adiposity [10]. Cardiorespiratory fitness was reported to be negatively associated with diastolic BP; adolescents with higher fitness levels showed lower diastolic BP, and this negative association was independent of weight status [14]. Muntner et al. [9] stated that elevated BP in children and adolescents has increased over the past few decades, and this increase has been attributed to the rise in overweight and obesity. Hence, weight reduction has been identified as the primary intervention for obesity-related hypertension. Additionally, other lifestyle interventions, such as regular PA, dietary modifications, and reduction of sedentary activity have been recommended to reduce and/or prevent hypertension and prehypertension in children [21]. While we were not able to corroborate these findings in our study, it is worth emphasizing that we used a different statistical approach to test for the longitudinal relationships between cardiorespiratory fitness and sport participation with hypertension. Thus, while previous studies simply used initial cardiorespiratory fitness and sport participation to predict $\mathrm{BP}$ scores at a later stage, we focused on children who were normotensive at baseline and would develop hypertension at follow-up. We also used quite a conservative definition of hypertension, by categorizing only children into this category who were classified as hypertensive for both systolic and diastolic BP.

\section{Strengths and Limitations}

The strengths of our study include the large sample as well as the validated methods for measuring cardiorespiratory fitness and BP. Another advantage, we think, is our focus on participants from disadvantaged areas, a so far under-researched study population. Accordingly, the SES of the participants of our study was low and homogenous. Furthermore, we used prospective data, focused on children who were initially normal weight and non-hypertensive, took into account the nested nature of our data, and ensured that all regression analyses were controlled for potential confounders. Because the main purpose of the DASH study was to examine the efficacy of a school-based health promotion program (including a physical activity component) on children's health and development, we explicitly focused on extracurricular exercise/sport participation in the present paper (not overall moderate-to-vigorous PA). Accordingly, in the longitudinal analyses, we were able to distinguish between the effects of the intervention versus those of extra-curricular exercise/sport participation, without running the risk of confounding these two variables.

Despite these strengths, the findings of our study must be interpreted with caution due to several limitations. First, although BP readings were taken after the children had been seated for approximately 
5 min., results might have increased slightly due to children experiencing an unfamiliar situation. However, most research conducted in children report the same limitation. Second, our study was conducted in only one province of South Africa. Therefore, our findings cannot be generalized to the entire country and elsewhere in Africa. Moreover, the findings cannot be generalized to include children attending more wealthy schools. Third, we used a subjective measure to assess children's sport participation. Thus, in future research, it would be interesting to replicate our findings with device-based measures (e.g., accelerometry). Fourth, while the item to assess extra-curricular exercise/sport participation was successfully used in studies with European children/adolescents [41], no previous validation was performed with African children. Nevertheless, our findings support that extra-curricular exercise/sport participation may constitute a relevant health resource among South African youth. Finally, we also acknowledge that given the simplicity of the item to assess extra-curricular sport participation, only information was available for frequency, but not for duration of this activity.

In spite of these shortcomings, the study brought valuable information to the fore regarding the current prevalence of hypertension and overweight/obesity among children from Port Elizabeth living in disadvantaged areas and how cardiorespiratory fitness contributes to the prevention of overweight/obesity among initially normal weight children.

\section{Conclusions}

This study confirms the existence of hypertension and overweight in a significant proportion of South African children from disadvantaged areas. Children with high cardiorespiratory fitness and sport participation are less likely to be classified as overweight/obese, and children who participate regularly in exercise and sport outside school hours are less likely to have hypertension. While our cross-sectional analyses revealed a clear link with these two cardiovascular health risk markers, the pattern of findings was less clear in the longitudinal analyses. Whereas (initially) normal weight children with high cardiorespiratory fitness at baseline or those who decreased less in cardiorespiratory fitness until post-intervention were at a lower risk of becoming overweight/obese, such preventive effects were not found for hypertension or for sport participation. Similarly, while the school-based PA intervention contributed to the prevention of overweight/obesity, no such preventive effect was found for hypertension. It is well possible that these associations establish earlier or that the follow-up period was too short to bring to light such a relationship. It might also be that other factors are stronger predictors than sport participation. Nevertheless, these findings highlight the importance of children participating in regular PA and maintaining their cardiorespiratory fitness levels. In view of the health implications of these findings, early identification of children with elevated BP is important, as is timely interventions to reduce overweight/obesity that may persist to adulthood. Preventing childhood overweight/obesity may also be seen as a way to reduce the risk of developing hypertension later in life. Future research should investigate other factors that might contribute to high BP in children.

Author Contributions: Conceptualization, S.N. and M.G.; methodology, C.W., R.d.R., I.M., H.S., P.S., N.P.-H., J.U., U.P., and M.G.; validation and formal analysis, M.G. and S.N.; investigation, resources, and data curation, S.N., L.A., J.D., S.G., M.G., N.J., I.M., and D.S.; writing-original draft preparation, S.N. and M.G.; writing-review and editing, C.W., R.d.R., A.A., L.A., J.D., S.G., Z.G., N.J., I.M., D.S., H.S., P.S., N.P.-H., J.U., U.P., and M.G.; visualization, S.N. and M.G.; supervision, M.G., C.W., and R.d.R.; project administration, S.N., L.A., J.D., S.G., N.J., I.M., and D.S.; funding acquisition, C.W. and U.P. All authors have read and agreed to the published version of the manuscript.

Funding: This study was conducted within the scope of the Swiss-South African Joint Research Program (SSAJRP). Financial support was provided by the Swiss National Science Foundation (SNSF, project no. IZLSZ3 149015) and the South African National Research Foundation (NRF, project no. 87397). The funders played no role in the study design, data collection and data analysis, data interpretation, and preparation of the manuscript or decision to publish. The corresponding author had the responsibility for the decision to submit for publication.

Acknowledgments: The authors are grateful to the children and parents/guardians for their willingness to participate in the study.

Conflicts of Interest: The authors declare no conflict of interest. 


\section{Appendix A}

Table A1. Changes with regard to body mass index (BMI) and hypertension classification from baseline to follow-up.

\begin{tabular}{|c|c|c|c|c|c|c|c|c|}
\hline \multicolumn{9}{|c|}{ BMI } \\
\hline \multicolumn{3}{|c|}{$\begin{array}{l}\text { Children who were normal weight at baseline ... } \\
\qquad(n=573)\end{array}$} & \multicolumn{3}{|c|}{ Children who were underweight at baseline $\ldots(n=35)$} & \multicolumn{3}{|c|}{$\begin{array}{l}\text { Children who were overweight/obese at baseline ... } \\
\qquad(n=146)\end{array}$} \\
\hline & $N$ & $\%$ & & $N$ & $\%$ & & $N$ & $\%$ \\
\hline $\begin{array}{l}\ldots \text { became underweight at } \\
\text { post-intervention. }\end{array}$ & 8 & 1.4 & $\begin{array}{l}\text {... were still underweight at } \\
\text { post-intervention. }\end{array}$ & 20 & 57.1 & $\begin{array}{l}\ldots \text { became underweight at } \\
\text { post-intervention. }\end{array}$ & 0 & 0.0 \\
\hline $\begin{array}{l}\text {... were still normal weight at } \\
\text { follow-up. }\end{array}$ & 532 & 92.4 & $\begin{array}{l}\ldots \text { became normal weight at } \\
\text { post-intervention. }\end{array}$ & 15 & 42.9 & $\begin{array}{l}\ldots \text { became normal weight at } \\
\text { post-intervention. }\end{array}$ & 12 & 8.2 \\
\hline $\begin{array}{l}\ldots \text { became overweight/obese at } \\
\text { post-intervention. }\end{array}$ & 33 & 5.7 & $\begin{array}{l}\ldots \text { became overweight/obese at } \\
\text { post-intervention. }\end{array}$ & 0 & 0.0 & $\begin{array}{l}\ldots \text { were still overweight/obese at } \\
\text { post-intervention. }\end{array}$ & 134 & 91.8 \\
\hline \multicolumn{9}{|c|}{ Systolic blood pressure } \\
\hline \multicolumn{3}{|c|}{ Children who were normotensive at baseline $\ldots(n=474)$} & \multicolumn{3}{|c|}{ Children who were pre-hypertensive at baseline $\ldots(n=43)$} & \multicolumn{3}{|c|}{ Children who were hypertensive at baseline $\ldots(n=165)$} \\
\hline $\begin{array}{c}\ldots \text { were still normotensive at } \\
\text { post-intervention. }\end{array}$ & 342 & 72.2 & $\begin{array}{c}\text {... became normotensive at } \\
\text { post-intervention. }\end{array}$ & 37 & 86.0 & $\begin{array}{l}\ldots \text { became normotensive at } \\
\text { post-intervention. }\end{array}$ & 136 & 82.4 \\
\hline $\begin{array}{l}\ldots \text { became prehypertensive at } \\
\text { post-intervention. }\end{array}$ & 34 & 7.2 & $\begin{array}{l}\ldots \text { were still pre-hypertensive at } \\
\text { post-intervention. }\end{array}$ & 2 & 4.7 & $\begin{array}{l}\ldots \text { became prehypertensive at } \\
\text { post-intervention. }\end{array}$ & 8 & 9.7 \\
\hline $\begin{array}{l}\ldots \text { became hypertensive at } \\
\text { post-intervention. }\end{array}$ & 98 & 20.6 & $\begin{array}{l}\ldots \text { became hypertensive at } \\
\text { post-intervention. }\end{array}$ & 4 & 9.3 & $\begin{array}{l}\ldots \text { were still hypertensive at } \\
\text { post-intervention. }\end{array}$ & 21 & 12.7 \\
\hline \multicolumn{9}{|c|}{ Diastolic blood pressure } \\
\hline \multicolumn{3}{|c|}{ Children who were normotensive at baseline $\ldots(n=456)$} & \multicolumn{3}{|c|}{ Children who were pre-hypertensive at baseline $\ldots(n=49)$} & \multicolumn{3}{|c|}{ Children who were hypertensive at baseline $\ldots(n=176)$} \\
\hline $\begin{array}{l}\ldots \text { were still normotensive at } \\
\text { post-intervention. }\end{array}$ & 306 & 67.1 & $\begin{array}{l}\text {... became normotensive at } \\
\text { post-intervention. }\end{array}$ & 37 & 74.0 & $\begin{array}{c}\text {... became normotensive at } \\
\text { post-intervention. }\end{array}$ & 127 & 72.1 \\
\hline $\begin{array}{l}\text {. became prehypertensive at } \\
\text { post-intervention. }\end{array}$ & 34 & 7.5 & $\begin{array}{l}\text {... were still pre-hypertensive at } \\
\text { post-intervention. }\end{array}$ & 6 & 14.0 & $\begin{array}{l}\ldots \text { became prehypertensive at } \\
\text { post-intervention. }\end{array}$ & 9 & 5.1 \\
\hline $\begin{array}{l}\ldots \text { became hypertensive at } \\
\text { post-intervention. }\end{array}$ & 116 & 25.4 & $\begin{array}{l}\ldots \text { became hypertensive at } \\
\text { post-intervention. }\end{array}$ & 6 & 12.0 & $\begin{array}{l}\ldots \text { were still hypertensive at } \\
\text { post-intervention. }\end{array}$ & 40 & 22.7 \\
\hline \multicolumn{9}{|c|}{ Systolic and diastolic blood pressure (combined index) } \\
\hline \multicolumn{3}{|c|}{ Children who were normotensive at baseline $\ldots(n=583)$} & \multicolumn{3}{|c|}{ Children who were hypertensive at baseline $\ldots(n=99)$} & & & \\
\hline ... were still normotensive at follow-up. & 520 & 89.2 & $\begin{array}{l}\text {.. became normotensive at } \\
\text { post-intervention. }\end{array}$ & 91 & 91.9 & & & \\
\hline $\begin{array}{l}\ldots \text { became hypertensive at } \\
\text { post-intervention. }\end{array}$ & 63 & 10.8 & $\begin{array}{l}\ldots \text { were still hypertensive at } \\
\text { post-intervention. }\end{array}$ & 8 & 8.1 & & & \\
\hline
\end{tabular}




\section{Appendix B}

Table A2. Cross-sectional multivariate relationships between exercise/sport participation, $\mathrm{VO}_{2} \mathrm{max}$, $\mathrm{BMI}$, and hypertension at baseline, before and after controlling for social and demographic background, odds ratio (OR), and 95\% confidence intervals (CI).

\begin{tabular}{|c|c|c|c|c|}
\hline \multirow[t]{2}{*}{ Risk of Being Classified as ... } & \multicolumn{2}{|c|}{$\ldots$ Overweight/Obese $^{\text {a }}(n=160$ of 853 Children; $18.8 \%$ ) } & \multicolumn{2}{|c|}{$\ldots$ Hypertensive ${ }^{\text {a }}(n=114$ of 842 Children; $13.5 \%)$} \\
\hline & $\operatorname{Exp}(B)$ & $95 \%$ CI for $\operatorname{Exp}(B)$ & $\operatorname{Exp}(B)$ & $95 \%$ CI for $\operatorname{Exp}(B)$ \\
\hline Cardiorespiratory fitness & $0.85^{* * *}$ & $(0.80$ to 0.89$)$ & 0.98 & (0.93 to 1.03$)$ \\
\hline Exercise/sport participation & $0.85^{* * *}$ & $(0.79$ to 0.93$)$ & $0.83 * * *$ & $(0.76$ to 0.91$)$ \\
\hline \multicolumn{5}{|c|}{ Model 2: Controlled for social and demographic background ${ }^{a}$} \\
\hline & $\operatorname{Exp}(B)$ & $95 \%$ CI for $\operatorname{Exp}(B)$ & $\operatorname{Exp}(B)$ & $95 \%$ CI for $\operatorname{Exp}(B)$ \\
\hline Cardiorespiratory fitness & $0.79 * * *$ & $(0.74$ to 0.84$)$ & 0.97 & $(0.92$ to 1.02$)$ \\
\hline Exercise/sport participation & $0.85^{* * *}$ & $(0.79$ to 0.92$)$ & $0.83^{* * *}$ & $(0.76$ to 0.90$)$ \\
\hline Age & $0.50^{* * *}$ & $(0.39$ to 0.63$)$ & 0.80 & (0.63 to 1.01 \\
\hline Gender (boys = reference) & $0.61^{* * *}$ & (0.41 to 0.93$)$ & 0.87 & (0.55 to 1.38$)$ \\
\hline Socioeconomic status & $1.16^{* * *}$ & (1.04 to 1.29$)$ & $0.91 *$ & (0.83 to 0.99$)$ \\
\hline
\end{tabular}

Notes. ${ }^{a}$ All analyses controlled for class-in-school (random intercept) to account for the nested nature of the data. ${ }^{*} p<0.05 .{ }^{* * *} p<0.001$. 


\section{Appendix C}

Table A3. Longitudinal multivariate relationships between exercise/sport participation, $\mathrm{VO}_{2} \mathrm{max}$, $\mathrm{BMI}$, and hypertension at baseline, before and after controlling for intervention condition (PA versus no PA, social and demographic background, odds ratio (OR), and 95\% confidence intervals (CI).

\begin{tabular}{|c|c|c|c|c|}
\hline \multirow[t]{2}{*}{ Risk of Being Classified as ... } & \multicolumn{2}{|c|}{$\begin{array}{c}\ldots \text { Overweight/Obese at Post-Intervention }{ }^{\mathrm{a}, \mathrm{c}}(n=36 \\
\text { of } 611 \text { Children; } 5.9 \%)\end{array}$} & \multicolumn{2}{|c|}{$\begin{array}{l}\text {... Hypertensive at Post-Intervention }{ }^{b, c}(n=63 \text { of } \\
583 \text { Children; } 10.8 \%)\end{array}$} \\
\hline & $\operatorname{Exp}(B)$ & $95 \%$ CI for $\operatorname{Exp}(B)$ & $\operatorname{Exp}(B)$ & $95 \%$ CI for $\operatorname{Exp}(B)$ \\
\hline Cardiorespiratory fitness (baseline) & $0.77^{* * *}$ & $(0.68$ to 0.88$)$ & 1.04 & (0.97 to 1.11$)$ \\
\hline Cardiorespiratory fitness (change) & $0.87 *$ & $(0.77$ to 0.98$)$ & 1.00 & (0.93 to 1.08$)$ \\
\hline Exercise/sport participation (baseline) & 0.95 & (0.74 to 1.22$)$ & 0.96 & (0.81 to 1.15$)$ \\
\hline Exercise/sport participation (change) & 1.06 & (0.88 to 1.28$)$ & 0.96 & (0.84 to 1.10$)$ \\
\hline \multicolumn{5}{|c|}{ Model 2: Controlled for social and demographic background ${ }^{c}$} \\
\hline Cardiorespiratory fitness (baseline) & $0.74^{* * *}$ & (0.63 to 0.87$)$ & 1.04 & $(0.96$ to 1.13$)$ \\
\hline Cardiorespiratory fitness (change) & $0.85 *$ & (0.75 to 0.97$)$ & 1.01 & (0.94 to 1.09$)$ \\
\hline Exercise/sport participation (baseline) & 1.00 & (0.18 to 1.29$)$ & 0.95 & (0.79 to 1.14$)$ \\
\hline Exercise/sport participation (change) & 1.06 & (0.89 to 1.28$)$ & 0.95 & (0.83 to 1.10$)$ \\
\hline Intervention condition $($ control $=$ reference $)$ & $0.36^{*}$ & (0.14 to 0.92$)$ & 1.31 & (0.75 to 2.29$)$ \\
\hline Age & 0.63 & (0.40 to 1.08$)$ & 1.12 & (0.81 to 1.54$)$ \\
\hline Gender (male = reference) & 1.00 & (0.40 to 2.73$)$ & 0.95 & (0.50 to 1.82$)$ \\
\hline Socioeconomic status & 0.98 & (0.81 to 1.19$)$ & 1.09 & (0.94 to 1.26$)$ \\
\hline
\end{tabular}

Notes. ${ }^{a}$ Only children included who were not classified overweight/obese at baseline, and with complete BMI data at baseline and follow-up $(n=611)$. ${ }^{\mathrm{b}}$ Only children included who were classified as normotensive at baseline, and with complete blood pressure data at baseline and follow-up $(n=583)$. ${ }^{\mathrm{c}}$ All analyses controlled for class-in-school (random intercept) to account for the nested nature of the data. ${ }^{*} p<0.05 .{ }^{* * *} p<0.001$. 


\section{References}

1. Ogden, C.L.; Flegal, K.M.; Carroll, M.D.; Johnson, C.L. Prevalence and trends in overweight among US children and adolescents, 1999-2000. JAMA 2002, 288, 1728-1732. [CrossRef] [PubMed]

2. Falkner, B. Children and adolescents with obesity-associated high blood pressure. J. Am. Soc. Hypertens. 2008, 2, 267-274. [CrossRef] [PubMed]

3. Armstrong, M.; Lambert, M.; Lambert, M. Secular trends in the prevalence of stunting, overweight and obesity among South African children (1994-2004). Eur. J. Clin. Nutr. 2011, 65, 835-840. [CrossRef] [PubMed]

4. Monyeki, K.; Kemper, H.; Makgae, P. The association of fat patterning with blood pressure in rural South African children: The Ellisras Longitudinal Growth and Health Study. Int. J. Epidemiol. 2006, 35, 114-120. [CrossRef]

5. Kemp, C.; Pienaar, A.E.; Schutte, A.E. The prevalence of hypertension and the relationship with body composition in Grade 1 learners in the North West Province of South Africa. S. Afr. J. Sports Med. 2011, 23, 117-122. [CrossRef]

6. Gerber, M.; Müller, I.; Walter, C.; du Randt, R.; Adams, L.; Gall, S.; Joubert, N.; Nqweniso, S.; Smith, D.; Steinmann, P. Physical activity and dual disease burden among South African primary schoolchildren from disadvantaged neighbourhoods. Prev. Med. 2018, 112, 104-110. [CrossRef]

7. Juhola, J.; Magnussen, C.G.; Viikari, J.S.; Kähönen, M.; Hutri-Kähönen, N.; Jula, A.; Lehtimäki, T.; Åkerblom, H.K.; Pietikäinen, M.; Laitinen, T. Tracking of serum lipid levels, blood pressure, and body mass index from childhood to adulthood: The Cardiovascular Risk in Young Finns Study. J. Pediatrics 2011, 159, 584-590. [CrossRef]

8. Kagura, J.; Adair, L.S.; Musa, M.G.; Pettifor, J.M.; Norris, S.A. Blood pressure tracking in urban black South African children: Birth to twenty cohort. BMC Pediatrics 2015, 15, 78-84. [CrossRef]

9. Muntner, P.; He, J.; Cutler, J.A.; Wildman, R.P.; Whelton, P.K. Trends in blood pressure among children and adolescents. JAMA 2004, 291, 2107-2113. [CrossRef]

10. Ekelund, U.; Anderssen, S.; Froberg, K.; Sardinha, L.B.; Andersen, L.B.; Brage, S.; Group, E.Y.H.S. Independent associations of physical activity and cardiorespiratory fitness with metabolic risk factors in children: The European youth heart study. Diabetologia 2007, 50, 1832-1840. [CrossRef]

11. Herman, K.M.; Craig, C.L.; Gauvin, L.; Katzmarzyk, P.T. Tracking of obesity and physical activity from childhood to adulthood: The Physical Activity Longitudinal Study. Int. J. Pediatrics Obes. 2009, 4, 281-288. [CrossRef] [PubMed]

12. Lurbe, E.; Agabiti-Rosei, E.; Cruickshank, J.K.; Dominiczak, A.; Erdine, S.; Hirth, A.; Invitti, C.; Litwin, M.; Mancia, G.; Pall, D. 2016 European Society of Hypertension guidelines for the management of high blood pressure in children and adolescents. J. Hypertens. 2016, 34, 1887-1920. [CrossRef] [PubMed]

13. Ho, M.; Garnett, S.P.; Baur, L.; Burrows, T.; Stewart, L.; Neve, M.; Collins, C. Effectiveness of lifestyle interventions in child obesity: Systematic review with meta-analysis. Pediatrics 2012, 130, e1647-e1671. [CrossRef] [PubMed]

14. Awotidebe, A.; Monyeki, M.; Moss, S.; Strydom, G.; Amstrong, M.; Kemper, H. Relationship of adiposity and cardiorespiratory fitness with resting blood pressure of South African adolescents: The PAHL Study. J. Hum. Hypertens. 2016, 30, 245-251. [CrossRef] [PubMed]

15. O’Donovan, G.; Hillsdon, M.; Ukoumunne, O.C.; Stamatakis, E.; Hamer, M. Objectively measured physical activity, cardiorespiratory fitness and cardiometabolic risk factors in the Health Survey for England. Prev. Med. 2013, 57, 201-205. [CrossRef] [PubMed]

16. Agostinis-Sobrinho, C.; Ruiz, J.R.; Moreira, C.; Abreu, S.; Lopes, L.; Oliveira-Santos, J.; Mota, J.; Santos, R. Cardiorespiratory fitness and blood pressure: A longitudinal analysis. J. Pediatrics 2018, 192, 130-135. [CrossRef]

17. Gerber, M.; Börjesson, M.; Ljung, T.; Lindwall, M.; Jonsdottir, I.H. Fitness moderates the relationship between stress and cardiovascular risk factors. Med. Sci. Sports Exerc. 2016, 48, 2075-2081. [CrossRef]

18. Yap, P.; Müller, I.; Walter, C.; Seelig, H.; Gerber, M.; Steinmann, P.; Damons, B.; Smith, D.; Gall, S.; Bänninger, D.; et al. Disease, Activity and Schoolchildren's Health (DASH) in Port Elizabeth, South Africa: A study protocol. BMC Public Health 2015, 15, 1285-1296. [CrossRef]

19. WHO. Growth Reference 5-19 Years; World Health Organization: Geneva, Switzerland, 2007. 
20. Neuhauser, H.K.; Thamm, M.; Ellert, U.; Hense, H.W.; Rosario, A.S. Blood pressure percentiles by age and height from nonoverweight children and adolescents in Germany. Pediatrics 2011, 127, e978-e988. [CrossRef]

21. Falkner, B.; Daniels, S.R.; Flynn, J.T.; Gidding, S.; Green, L.A.; Ingelfinger, J.R.; Lauer, R.M.; Morgenstern, B.Z.; Portman, R.J.; Prineas, R.J. The fourth report on the diagnosis, evaluation, and treatment of high blood pressure in children and adolescents. Pediatrics 2004, 114, 555-576. [CrossRef]

22. Agyemang, C.; Redekop, W.K.; Owusu-Dabo, E.; Bruijnzeels, M.A. Blood pressure patterns in rural, semi-urban and urban children in the Ashanti region of Ghana, West-Africa. BMC Public Health 2005, 5. [CrossRef] [PubMed]

23. Council of Europe. Testing Physical Fitness: Eurofit Experimental Battery; Council of Europe: Strasbourg, France, 1983.

24. Léger, L.A.; Mercier, D.; Gadoury, C.; Lambert, J. The multistage 20 meter shuttle run test for aerobic fitness. J. Sports Sci. 1988, 6, 93-101. [CrossRef] [PubMed]

25. Mayorga-Vega, D.; Aguilar-Soto, P.; Viciana, J. Criterion-related validity of the 20-m Shuttle Run Test for estimating cardiorespiratory fitness: A meta-analysis. J. Sport Sci. Med. 2015, 14, 536-547.

26. Liu, N.S.; Plwman, S.A.; Looney, M.A. The reliability and validity of the 20-meter shuttle test in American students 12-15 years old. Res. Q. Exerc. Sport 1992, 63, 360-365. [CrossRef]

27. Inchley, J.; Currie, D.; Young, T.; Samdal, O.; Torsheim, T.; Auguston, L. Growing up unequal: Gender and socioeconomic differences in young people's health and well-being. Health Behavior in School-aged Children (HBSC) study: International report from the 2013/2014 survey. In Health Policy for Children and Adolescents; WHO: Geneva, Switzerland, 2016.

28. Prochaska, J.J.; Sallis, J.F.; Long, B. A physical activity screening measure for use with adolescents in primary care. Arch. Pediatrics Adolesc. Med. 2001, 155, 554-559. [CrossRef]

29. Galan, I.; Boix, R.; Medrano, M.J.; Ramos, P.; Rivera, F.; Pastor-Barriuso, R.; Moreno, C. Physical activity and self-reported health status among adolescents: A cross-sectional population-based study. BMJ Open 2013, 3, e002644. [CrossRef]

30. Kimani-Murage, E.; Kahn, K.; Pettifor, J.; Tollman, S.; Dunger, D.; Gómez-Olivé, X.; Norris, S. The prevalence of stunting, overweight and obesity, and metabolic disease risk in rural South African children. BMC Public Health 2010, 10, 158-170. [CrossRef]

31. Kruger, R.; Kruger, H.; Macintyre, U. The determinants of overweight and obesity among 10-to 15-year-old schoolchildren in the North West Province, South Africa-the THUSA BANA (Transition and Health during Urbanisation of South Africans; BANA, children) study. Public Health Nutr. 2006, 9, 351-358. [CrossRef]

32. Okoh, B.A.; Alikor, E.A.; Akani, N. Prevalence of hypertension in primary school-children in Port Harcourt, Nigeria. Paediatrics Int. Child Health 2012, 32, 208-212. [CrossRef]

33. Ellenga Mbolla, B.F.; Okoko, A.R.; Mabiala Babela, J.R.; Ekouya Bowassa, G.; Gombet, T.R.; Kimbally-Kaky, S.-G.; Longo-Mbenza, B. Prehypertension and hypertension among schoolchildren in Brazzaville, Congo. Int. J. Hypertens. 2014, 2014. [CrossRef]

34. MacIntyre, U.; Kruger, H.; Venter, C.; Vorster, H. Dietary intakes of an African population in different stages of transition in the North West Province, South Africa: The THUSA study. Nutr. Res. 2002, 22, 239-256. [CrossRef]

35. Steyn, N.; Mchiza, Z. Obesity and the nutrition transition in Sub-Saharan Africa. Ann. N. Y. Acad. Sci. 2014, 1311, 88-101. [CrossRef]

36. Meininger, J.C.; Brosnan, C.A.; Eissa, M.A.; Nguyen, T.Q.; Reyes, L.R.; Upchurch, S.L.; Phillips, M.; Sterchy, S. Overweight and central adiposity in school-age children and links with hypertension. J. Pediatric Nurs. 2010, 25, 119-125. [CrossRef] [PubMed]

37. Reilly, J.J.; Kelly, J. Long-term impact of overweight and obesity in childhood and adolescence on morbidity and premature mortality in adulthood: Systematic review. Int. J. Obes. 2011, 35, 891-898. [CrossRef] [PubMed]

38. Li, X.-H.; Lin, S.; Guo, H.; Huang, Y.; Wu, L.; Zhang, Z.; Ma, J.; Wang, H.-J. Effectiveness of a school-based physical activity intervention on obesity in school children: A nonrandomized controlled trial. BMC Public Health 2014, 14, 1282. [CrossRef]

39. Kriemler, S.; Zahner, L.; Schindler, C.; Meyer, U.; Hartmann, T.; Hebestreit, H.; Brunner-La Rocca, H.; van Mechelen, W.; Puder, J. Effect of school based physical activity programme (KISS) on fitness and adiposity in primary schoolchildren: Cluster randomised controlled trial. BMJ 2010, 340, c785-c792. [CrossRef] 
40. Dobbins, M.; Husson, H.; DeCorby, K.; LaRocca, R.L. School-Based Physical Activity Programs for Promoting Physical Activity and Fitness in Children and Adolescents Aged 6 to 18; The Cochrane Library: London, UK, 2013.

41. Haugland, S.; Wold, B.; Torsheim, T. Relieving the pressure? The role of physical activity in the relationship between school-related stress and adolescent health complaints. Res. Q. Exerc. Sport 2003, 74, 127-135. [CrossRef] 